\title{
Development and Validation of HPLC Method for Simultaneous Determination of Gliclazide and Enalapril Maleate in Tablet Dosage Form
}

\author{
Md. Abdullah Al Mahmud ${ }^{1}$, Subrata Bhadra ${ }^{2}$, Afroza Haque ${ }^{2}$, \\ Md. Elias-Al-Mamun ${ }^{2}$ and Syed Shabbir Haider ${ }^{2}$ \\ ${ }^{1}$ Department of Pharmacy, Primeasia University, 12 Kemal Ataturk Avenue, Banani, \\ Dhaka-1213, Bangladesh \\ ${ }^{2}$ Department of Pharmaceutical Technology, Faculty of Pharmacy, University of Dhaka, \\ Dhaka-1000, Bangladesh
}

Received: June 16, 2014; Accepted: June 25, 2014; Published (web): June 29, 2014

\begin{abstract}
This paper describes a simple, sensitive and selective high performance liquid chromatographic (HPLC) method for the separation and determination of gliclazide (GLI) and enalapril (ENA) maleate simultaneously in tablet dosage forms. The chromatographic separation was performed on an ODS column $(250 \mathrm{~mm} \times 4.6 \mathrm{~mm}$ i.d., 5 $\mu \mathrm{m}$ particle size) at $40 \pm 0.5^{\circ} \mathrm{C}$, with a mobile phase composed of phosphate buffer ( $\mathrm{pH} 4.4$ ), acetonitrile and methanol in the ratio of 45:40:15, (v/v/v). The flow rate was maintained at $1.5 \mathrm{ml} / \mathrm{min}$, injected volume was $20 \mu 1$ and detection wavelength was $217 \mathrm{~nm}$. The method was validated according to ICH Q2 (R1) guidelines and found to be linear over a range of $40-120 \mu \mathrm{g} / \mathrm{ml}\left(\mathrm{R}^{2}=0.991\right)$ and $2.5-7.5 \mu \mathrm{g} / \mathrm{ml}\left(\mathrm{R}^{2}=0.998\right)$ for gliclazide and enalapril maleate, respectively. The proposed method was applied successfully for the assay of these two drugs in their combined inhouse developed tablet formulations and could be applicable for routine quality control analysis.
\end{abstract}

Key words: Gliclazide, enalapril maleate, HPLC, method development, validation

\section{INTRODUCTION}

Patients with diabetes mellitus have an increased prevalence of hypertension and associated cardiovascular disease (CVD). ${ }^{1}$ An international investigation revealed that hypertension affects about $60 \%$ of patients with type II diabetes. ${ }^{2}$ A limited survey on the prescribing pattern of diabetichypertensive patients also disclosed the same trend in our country. ${ }^{3}$ In Bangladesh as well as globally, the physicians are prescribing the ACE inhibitors at a greater frequency in diabetic-hypertensive patients. ${ }^{2-5}$

The multi-component formulations have gained a lot of importance due to obvious benefits like increased patient compliance, convenience and cost savings. In recent days, the pharmaceutical industries are placing a greater emphasis on FDC dosage forms

Correspondence to: Syed Shabbir Haider

Tel: +880-2-9661920-73 Extn. 8184; Fax: +880-2-8615583

Email: haidersyedshabbir@yahoo.com

Dhaka Univ. J. Pharm. Sci. 13(1): 51-56, 2014 (June) and lots of such products are available in the consumer market, both locally and globally. ${ }^{6,7}$ Considering the prevalence of diabetic-hypertension as well as the prescribing pattern of drugs in patients suffering from such complications, it is apparent that antidiabetic and antihypertensive drugs seem to be potential candidates for incorporating in a FDC product. Based on a feasibility study, such a combination product was developed recently in our laboratory containing an oral hypoglycemic agent and an ACE inhibitor. Accordingly, an immediate release tablet containing $80 \mathrm{mg}$ gliclazide (GLI, a second generation sulfonylurea, Figure 1) and $5 \mathrm{mg}$ enalapril maleate (ENA, an oral prodrug that is converted by hydrolysis to enalaprilat, which is an ACE inhibitor, Figure 2) was formulated, prepared and evaluated for various pharmaceutical parameters including dissolution and stability testing. ${ }^{8}$ During the course of study, two analytical methods - based on UV spectroscopy and HPLC, were developed for 
the simultaneous estimation of these two drugs in the prepared tablets and in the dissolution medium during dissolution testing. The present paper reports the RPHPLC method developed for the determination of GLI and ENA in combination dosage form as per ICH Q2 (R1) guideline. ${ }^{9}$

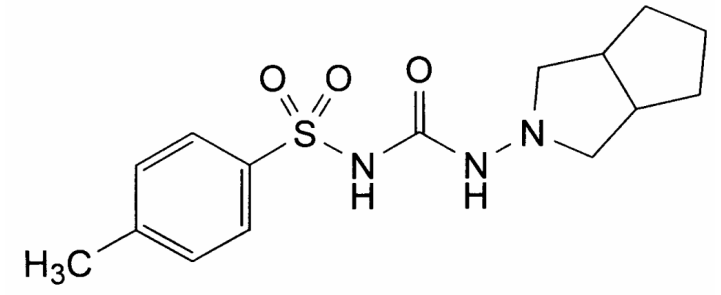

Figure 1. Structure of gliclazide (GLI)

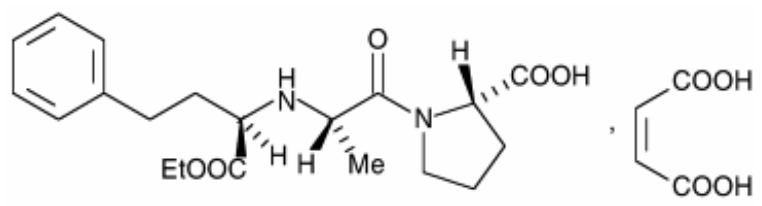

Figure 2. Structure of enalapril maleate (ENA)

\section{MATERIALS AND METHODS}

Materials. Gliclazide BP and enalapril maleate USP were of pharmacopeial grade and obtained from Laboratorio Chimico Internazionale SPA, Italy and Chematis Pharma Ltd., China, respectively. Potassium dihydrogen phosphate, acetonitrile and methanol were obtained from Scharlau, Spain. Phosphoric acid was purchased from Merck, Germany. All reagents and solvents were of HPLC or analytical grade.

Instrumentation and chromatographic conditions. A Shimadzu HPLC (Model: LC-2010 HT) integrated with variable wavelength programmable photo diode array (PDA) detector was employed for the analysis. The chromatographic analysis were performed on an ODS column (250 $\mathrm{mm}$ length $\times 4.6 \mathrm{~mm}$ ID with $5 \mu \mathrm{m}$ particle size) and the mobile phase was phosphate buffer of $\mathrm{pH} 4.4$, acetonitrile and methanol (45: $40: 15, \mathrm{v} / \mathrm{v} / \mathrm{v})$, pumped at a flow rate of $1.5 \mathrm{ml} / \mathrm{min}$. The column temperature was maintained at $40 \pm 0.5^{\circ} \mathrm{C}$, and the detection wavelength was $217 \mathrm{~nm}$. The injection volume was $10 \mu \mathrm{L}$, and the run time was $10 \mathrm{~min}$ for each injection.
Determination of analytical wavelength. In order to determine a suitable wave length to be used for the combined analysis of the drugs, $80 \mathrm{mg}$ of each of GLI and ENA were taken in a clean and dry 100 $\mathrm{ml}$ volumetric flask; suitably diluted with acetonitrile and mix well. $5 \mathrm{ml}$ of this solution was taken in a clean and dry $50 \mathrm{ml}$ volumetric flask and the volume was made up to the mark with acetonitrile. Then this solution, containing $80 \mu \mathrm{g} / \mathrm{ml}$ of each of GLI and ENA, was filtered through $0.45 \mu$ Whatman filter paper, injected and scanned in the range of 200-240 $\mathrm{nm}$ by PDA detector.

Preparation of mobile phase. Accurately weighted $6.8 \mathrm{~g}$ monobasic potassium phosphate was taken in a $1000 \mathrm{ml}$ volumetric flask, and the volume was made up to mark with distilled water and finally $\mathrm{pH}$ was adjusted to $4.4 \pm 0.1$ with suitably diluted orthophosphoric acid.

Preparation of working standard solution. Standard solution was prepared by transferring accurately weighed $80 \mathrm{mg}$ of GLI and $5 \mathrm{mg}$ of ENA in a $100 \mathrm{ml}$ clean and dry volumetric flask. About 70 $\mathrm{ml}$ of mobile phase was added as diluting solution and mixed well. Then the volume was made up to the mark. Accurately measured $5 \mathrm{ml}$ of this solution was further diluted to $50 \mathrm{ml}$ with same diluting solution to prepare a concentration of $80 \mu \mathrm{g} / \mathrm{ml}$ of GLI and 5 $\mu \mathrm{g} / \mathrm{ml}$ of ENA. After filtering through a $0.2 \mu$ disc filter, the solution was used as nominal standard solution for analysis.

\section{Method validation}

System suitability. The nominal standard solution containing $80 \mu \mathrm{g} / \mathrm{ml}$ of GLI and $5 \mu \mathrm{g} / \mathrm{ml}$ of ENA was injected and repeated six times. The peak area (A), resolution $\left(R_{s}\right)$, number of theoretical plates $(\mathrm{N})$, tailing factor $\left(\mathrm{t}_{\mathrm{f}}\right)$ and retention time $\left(\mathrm{R}_{\mathrm{t}}\right)$ were calculated to determine whether the result complies with the recommended limit.

Linearity. The linearity of measurement was analyzed through the standard curves ranging from $40-120 \mu \mathrm{g} / \mathrm{ml}$ for GLI and $2.5-7.5 \mu \mathrm{g} / \mathrm{ml}$ for ENA and carried out in triplicate. Three calibration curves were prepared at five different concentrations in the 
same day. The linearity was evaluated by linear regression analysis, which was calculated by the least-square regression analysis.

Specificity. Specificity of the method was determined by comparison between working standard solution and sample solution. Standard solution and sample solution of $80 \mu \mathrm{g} / \mathrm{ml}$ of GLI and $5 \mu \mathrm{g} / \mathrm{ml}$ of ENA were injected to the HPLC system for triplicates and were analyzed. Peak purity tool was used to investigate the interference of any other peak(s) with the standard chromatograms.

Noninterference of placebo and blank solution. Placebo solution was prepared in the same way of the sample solution in presence of all inactive ingredients of the experimental tablet formulation without the incorporation of two active ingredients (e. g. GLI and ENA) to check the noninterference of placebo. Blank solution was treated in the same way of the standard solution and was injected to check the noninterference of blank (if any).

Accuracy (Recovery test). Accuracy study was carried out for both drug and drug-matrix solutions. In case of drug solution, standard solutions of GLI and ENA, corresponding to 80,100 and $130 \%$ of the nominal analytical concentration of the drugs were compared with reference standard solution of GLI and ENA of known purity ( $80 \mu \mathrm{g} / \mathrm{ml}$ of GLI and 5 $\mu \mathrm{g} / \mathrm{ml}$ of ENA), and the percent recoveries (mean \pm $\%$ RSD) of both drugs in pure form were calculated $(n=3)$. In case of drug-matrix solution, accuracy study of the proposed method was carried out by the recovery test, which consisted of adding known amounts of working standards, e.g. GLI and ENA, to the placebo solutions in the beginning of the process. This test was realized by assaying three different solutions, three replicates each, containing 50, 100, and $150 \%$ of the nominal analytical concentrations of the working standards $(80 \mu \mathrm{g} / \mathrm{ml}$ of GLI and $5 \mu \mathrm{g} / \mathrm{ml}$ of ENA), and then percent recoveries (mean \pm $\%$ RSD) in drug-matrix solutions were calculated $(n=3)$.

Precision. The repeatability (intra-day precision) of the method was evaluated by analyzing separately six nominal standard solutions of GLI and ENA on the same day and the intermediate precision (interday precision) was evaluated at same nominal standard concentrations daily for six times in three consecutive days. The concentrations of GLI and ENA were then determined and the standard deviations (SD) and relative standard deviations (RSD) were calculated.

Sensitivity. To calculate limits of detection (LOD) and limits of quantitation (LOQ) of GLI and ENA, sequential dilutions were done and analyzed by the proposed method. The LOD $(k=3.3)$ and LOQ $(k$ $=10$ ) were calculated by calibration curve method using the following equation:

$\mathrm{A}=\mathrm{k} \sigma / \mathrm{S}$ where, 'A' is LOD or LOQ, $\sigma$ is the standard deviation of the response, and ' $\mathrm{S}$ ' is the slope of the calibration curve.

\section{RESULTS AND DISCUSSION}

Selection of analytical wavelength. A chart of GLI and ENA representing the relation between the peak area (y) versus experimental wavelengths (x) studied in the range of 200-240 nm was constructed. The result, shown in Figure 3, represents that at 217 $\mathrm{nm}$ both drugs provided equal response and was taken as the experimental wavelength during subsequent analytical study.

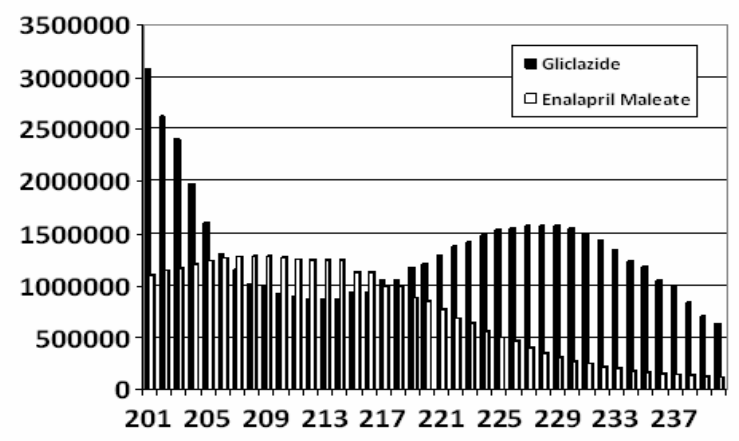

Figure 3. Chart representing the relationship between peak area $v s$. experimental wavelength

\section{Method validation}

System suitability. The chromatographic parameters, such as peak area, resolution, number of theoretical plates, tailing factors and retention times were calculated for the standard solution. The results 
(Mean $\pm \%$ RSD) are shown in Table 1, indicating the good performance of the system.

Linearity. The linear regression equation for GLI was found to be $\mathrm{Y}=18870 \mathrm{X}+13575$; whereas for ENA was $\mathrm{Y}=2200 \mathrm{X}+1635$ with correlation coefficients $\left(\mathrm{R}^{2}\right)$ were 0.991 and 0.998 for GLI and ENA, respectively. The results of the regression analysis were statistically significant. The validity of the assay was verified by means of ANOVA and no deviation from linearity was found $(P<0.05)$.
Specificity. Standard solution and sample solution of $80 \mu \mathrm{g} / \mathrm{ml}$ of GLI and $5 \mu \mathrm{g} / \mathrm{ml}$ of ENA were injected to the HPLC system and the chromatograms were recorded to check the peak purity. In every case, the peak purity was found 99.99\% demonstrating that other added compounds did not co-elute with the main peaks, hence the chromatograms of GLI and ENA were pure in all cases. Figure 4 shows the typical standard and sample chromatograms of GLI and ENA by the proposed method.
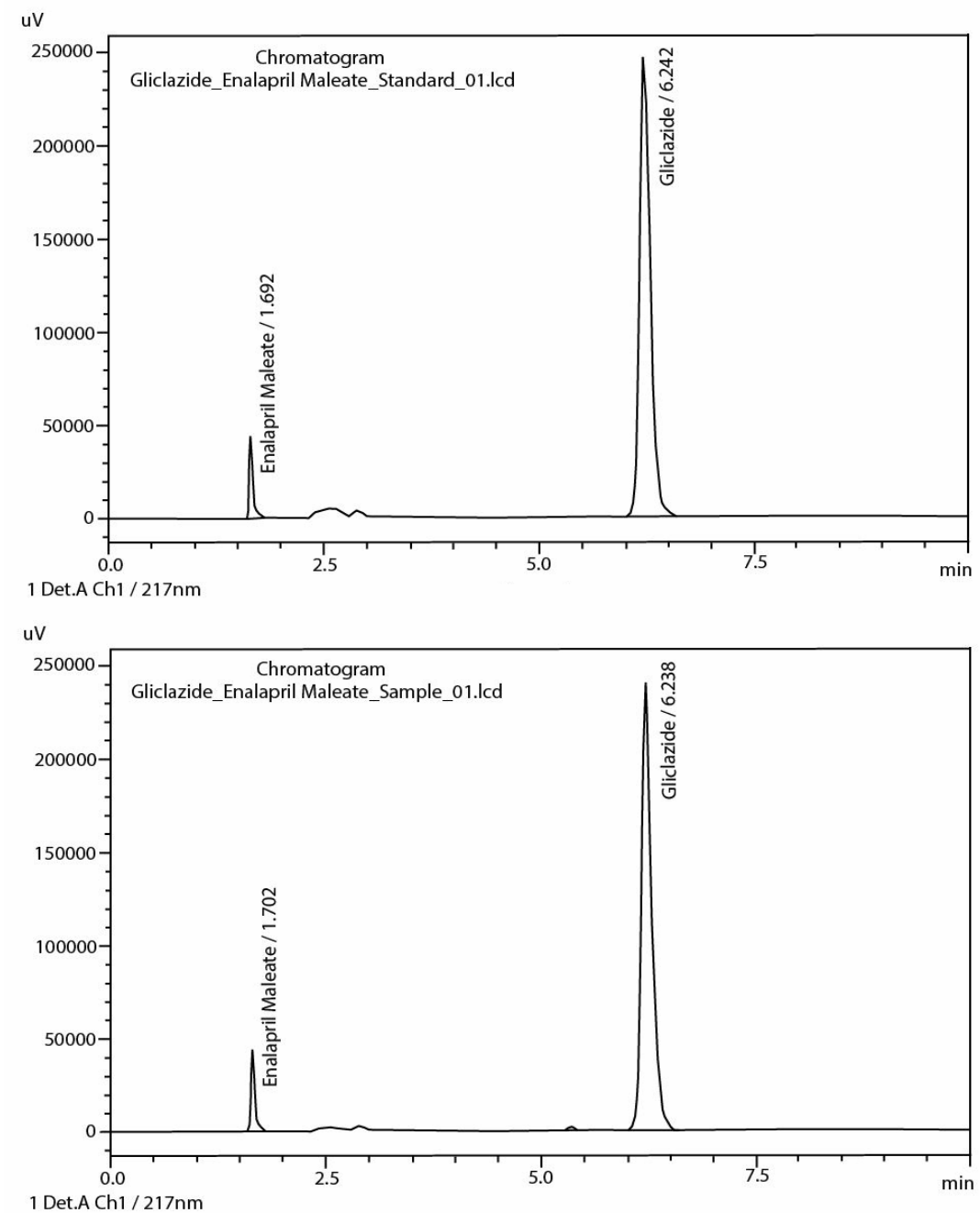

Figure 4. Chromatograms of standard and sample solutions at $217 \mathrm{~nm}$. Mobile phase was phosphate buffer $(\mathrm{pH} 4.4)$, acetonitrile and methanol in the ratio of $(45: 40: 15, \mathrm{v} / \mathrm{v} / \mathrm{v})$, flow rate was $1.5 \mathrm{ml} / \mathrm{min}$ and column temperature was $40 \pm 0.5^{\circ} \mathrm{C}$.

Noninterference of placebo and blank solution. Separately prepared placebo and blank solution were injected and their chromatograms were recorded to check the interference of inactive ingredients and diluting solution within the retention times around $1.7 \mathrm{~min}$ (ENA) and 6.25 (GLI) min. But the chromatograms revealed no peaks around the aforementioned times indicating that peaks of GLI 
and ENA by the proposed method were clearly separated from the response of any unwanted peak(s).

Accuracy. The overall results of percent recoveries (Mean $\pm \% \mathrm{RSD}$ ) at three levels of solutions of GLI and ENA in pure and drug-matrix solutions are given in Table 2, indicating that the proposed method is highly accurate and suitable for the intended use. The calculated recovery values of GLI and ENA ranged from $99.942 \%( \pm 0.064 \%)$ to $100.057 \%( \pm 0.059 \%)$ and $99.846 \%( \pm 0.267 \%)$ to $101.6 \%( \pm 1.052 \%)$ in pure forms, respectively, and from $100.203 \%( \pm 0.062 \%)$ to $100.308 \%( \pm 0.104 \%)$ and $101.156 \%( \pm 0.201 \%)$ to $101.6 \%( \pm 0.682 \%)$ in drug-matrix solutions, respectively.

Precision. The results obtained from intra-day and inter-day precision are presented in Table 3 .
Table 3 shows $\%$ RSD values with $2 \%$ which indicate that there was no significant difference between assays results of both GLI and ENA either within-day or between days, therefore, the proposed method was reliable and precise.

Table 1. System suitability parameters

\begin{tabular}{lcc}
\hline \multirow{2}{*}{ Parameters } & \multicolumn{2}{c}{ Values (Mean $\pm \%$ RSD)* } \\
\cline { 2 - 3 } & GLI & ENA \\
\hline $\begin{array}{l}\text { Peak area }(\mathrm{A}) \\
\text { Resolution }\left(\mathrm{R}_{\mathrm{s}}\right)\end{array}$ & $1657393 \pm 0.045$ & $111515 \pm 0.126$ \\
$\begin{array}{l}\text { No. of theoretical } \\
\text { plate }(\mathrm{N})\end{array}$ & $3844 \pm 0.199$ & $1427 \pm 0.423$ \\
$\begin{array}{l}\text { Tailing factor }\left(\mathrm{t}_{\mathrm{f}}\right) \\
\text { Retention time }\end{array}$ & $1.17 \pm 0.936$ & $1.08 \pm 0.754$ \\
$\left(\mathrm{R}_{\mathrm{t}}\right)$ & $6.25 \pm 0.351$ & $1.71 \pm 0.953$ \\
\hline
\end{tabular}

*Mean and \% Relative Standard Deviation of six replicates

Table 2. Accuracy studies of the proposed method in pure and drug-matrix solutions

\begin{tabular}{llccc}
\hline Drugs & Conditions & $\begin{array}{c}\text { Added amount } \\
(\mu \mathrm{g} / \mathrm{ml})\end{array}$ & $\begin{array}{c}\text { Amount recovered } \\
(\text { Mean } \pm \% \text { RSD }) *\end{array}$ & $\begin{array}{c}\text { \% Recovery } \\
(\text { Mean } \pm \% \text { RSD }) *\end{array}$ \\
\hline \multirow{4}{*}{ GLI } & Standard solution & 64 & $64.037 \pm 0.059$ & $100.057 \pm 0.059$ \\
& & 80 & $79.953 \pm 0.064$ & $99.942 \pm 0.064$ \\
& & 104 & $104.270 \pm 0.044$ & $100.260 \pm 0.044$ \\
\cline { 3 - 5 } & Drug-matrix solution & 40 & $40.123 \pm 0.104$ & $100.308 \pm 0.104$ \\
& & 80 & $80.180 \pm 0.057$ & $100.225 \pm 0.057$ \\
& & 120 & $120.243 \pm 0.062$ & $100.203 \pm 0.062$ \\
\hline \multirow{3}{*}{ SNA } & & 4 & $4.000 \pm 1.732$ & $100.000 \pm 1.732$ \\
& & 5 & $5.030 \pm 1.052$ & $100.600 \pm 1.052$ \\
& & 6.5 & $6.490 \pm 0.267$ & $99.846 \pm 0.267$ \\
\cline { 3 - 5 } & & 2.5 & $2.54 \pm 0.682$ & $101.600 \pm 0.682$ \\
& & 5 & $5.060 \pm 0.523$ & $101.200 \pm 0.523$ \\
& & 7.5 & $7.587 \pm 0.201$ & $101.156 \pm 0.201$ \\
\hline
\end{tabular}

*Mean $\pm \%$ RSD of three replicates

Table 3. Summary of intra-day and inter-day precision data

\begin{tabular}{lllllll}
\hline Drugs & $\begin{array}{l}\text { Spike } \\
\text { level }(\%)\end{array}$ & $\begin{array}{l}\text { Intra-day** } \\
(\text { Mean } \pm \% \text { RDS })\end{array}$ & \multicolumn{2}{l}{ Inter-day** $($ Mean $\pm \%$ RDS $)$} & Inter-day*** \\
\cline { 5 - 6 } & & & Day-1 & Day-2 & Day-3 & \\
\hline GLI & $100^{*}$ & $101.268 \pm 0.486$ & $101.268 \pm 0.486$ & $100.037 \pm 1.128$ & $100.093 \pm 1.26$ & $100.466 \pm 1.115$ \\
ENA & $100 *$ & $100.677 \pm 0.516$ & $100.677 \pm 0.516$ & $99.96 \pm 0.965$ & $99.138 \pm 0.713$ & $99.925 \pm 0.959$ \\
\hline
\end{tabular}

*Spike level $100 \%$ indicates $80 \mu \mathrm{g} / \mathrm{ml}$ for GLI and $5 \mu \mathrm{g} / \mathrm{ml}$ for ENA.

** Mean and \% RSD value of six determinations.

***(Overall Mean $\pm \%$ RDS $)$ means the arithmetic mean of inter-day results.

Sensitivity. According to the proposed method, the limit of detection (LOD) and limit of quantitation (LOQ) were calculated based on signal-to-noise ratio method and the values were found to be $11 \mathrm{ng} / \mathrm{ml}$ and
$35 \mathrm{ng} / \mathrm{ml}$ for GLI, respectively, and $41 \mathrm{ng} / \mathrm{ml}$ and 127 $\mathrm{ng} / \mathrm{ml}$ for ENA, respectively. 


\section{CONCLUSION}

The proposed RP-HPLC method was used for the simultaneous estimation of GLI and ENA in tablet dosage form was found to be simple, sensitive, accurate, and precise. The method was validated according to the ICH guidelines. A good separation was performed for ENA at $1.7 \mathrm{~min}$ and GLI at 6.2 min with correlation coefficients $\left(\mathrm{R}^{2}\right)$ were 0.998 and 0.991, respectively. Hence, the present RP-HPLC method may be used for investigational analysis and routine quality control analysis of GLI and ENA in pure and fixed dose combination tablet dosage forms.

\section{CONFLICT OF INTERESTS}

The authors declare that there are no conflicts of interest.

\section{REFERENCES}

1. Guzmán, C.B. and Sowers, J.R. 1999. Special considerations in the therapy of diabetic hypertension. Prog. Cardiovasc. Dis. 41, 461-470.

2. Johnson, M.L. and Singh, H. 2005. Patterns of antihypertensive therapy among patients with diabetes. $J$. Gen. Intern. Med. 20, 842-846.
3. Haque, A. Feasibility study of formulation and preparation of combined Gliclazide and Enalapril maleate immediate release tablet. M. Pharm. thesis 2008, submitted to Department of Pharmaceutical Technology, Faculty of Pharmacy, University of Dhaka.

4. Thamer, M., Ray, N.F. and Taylor, T. 1999. Association between antihypertensive drug use and hypoglycemia: a casecontrol study of diabetic users of insulin or sulfonylureas. Clin. Ther. 21, 1387-1400.

5. Shorr, R.I., Ray, W.A., Daugherty, J.R. and Griffin, M.R. 1997. Antihypertensives and the risk of serious hypoglycemia in older persons using insulin or sulfonylureas. J. Am. Med. 278, 40-43.

6. Miller, F.H. 2005. Combination products: Industry strategies and innovation takes combination products to new levels. In: Technology Overviews, Drug Delivery Report Autumn/ Winter, pp. 42-46.

7. Chakraborti, A. Fixed dose combinations in therapy. Express Pharma 2007; 1-15 August.

8. Elias-Al-Mamun, M., Haque, A. and Haider, S.S. Development and evaluation of combined gliclazide and enalapril maleate immediate release tablet. J. Pharm. Sci. Res. 3, 1103-1109, 2011

9. Validation of analytical procedures: Text and Methodology Q2(R1), In: ICH Harmonized Tripartite Guideline, Geneva, Switzerland, 2005. 